\title{
Nursing Leadership: Key to Systematic Efficiency
}

\author{
Guo-Qiong Liu ${ }^{1}$, Chao $\mathrm{He}^{1}$, Zhong Jia ${ }^{2 *}$, Yue Zhou ${ }^{3}$ \\ ${ }^{1}$ BA, Hangzhou First People's Hospital, Nanjing Medical University Affiliated Hangzhou Hospital \& Zhejiang Chinese \\ Medicine Affiliated Fourth Clinical Medical Hospital, Hangzhou, 310006, China. \\ ${ }^{2}$ PhD, Hangzhou First People's Hospital, Nanjing Medical University Affiliated Hangzhou Hospital \& Zhejiang Chinese \\ Medicine Affiliated Fourth Clinical Medical Hospital, Hangzhou, 310006, China. \\ ${ }^{3}$ MD, Hangzhou First People's Hospital, Nanjing Medical University Affiliated Hangzhou Hospital \& Zhejiang Chinese \\ Medicine Affiliated Fourth Clinical Medical Hospital, Hangzhou, 310006, China.
}

Received: January 02, 2018; Accepted: January 23, 2018; Published: February 08, 2018

*Corresponding author: Zhong Jia, Hangzhou First People's Hospital, Nanjing Medical University Affiliated Hangzhou Hospital \& Zhejiang Chinese Medicine Affiliated Fourth Clinical Medical Hospital, Hangzhou, 310006, China; Tel: +86-0571-87914773; E-mail: jiazhong20058@hotmail. com

\section{Background}

Current nursing is in a state of constant change and nurses' burnout rates reaching crisis levels. According to a survey on leadership, nearly $40 \%$ of respondents say their organization's leadership team is not doing enough to respond to change. Are nursing leaders the answer? Actually, organizations need responsible and skilled leaders at the helm, the only way to navigate through these difficult times is with excellent leadership at all levels of each organization.

\section{Aim}

To discuss how to elevate the leadership in nursing in accordance with information-based system to the constant change, and what the genuine nature of nursing leadership

\section{Methods}

How to address pressing issues in daily's providers, including unsustainable burnout rates; and how to create a highly responsive team? Now it is time to pay more attention to the flow of information-based systematic efficiency, which is highly regarded with nursing cooperation systems - share with you the secrets of leadership development that will help everyone transform their own perspective $[1,2]$.The tangible and actionable information tells us about what credentials (clinical or business) work best in intensive nursing leadership roles; How to lead physicians, how to identify those who want to become leaders, and what are the necessary skill sets. What are leaders' roles in responding to this competitive crisis. What strategies innovative leaders use to bolster their department's ability to respond to change As a result, of course, the real-world case studies, and an interactive Q\&A session with our industry-leading arts is needed. And big data-based artificial intelligence will help leadership become more convenient, scientific elements, accordingly benefit nurses, physicians as well as patients.

\section{Discussion}

In authors' opinion, overrating individual's abilities sometimes produce negative effects due to the lack of coordination and democracy as well. It may also defect the executive performance accordingly. In fact, assessment of team work is of more accuracy to judge an individual substantial role. Indeed, it may be a very awful situation if we insist on the same standard criterion to request everyone. Obviously, it's unfair and many staffs' innovative ideas may be curbed unconsciously.

In detail, nursing leaderships present as three parts: First, communication performance, which is one of the most effective adjustment, represents emotional intelligence of nursing leader. By which we aim to fulfill patients' basic dignity, privacy, human rights and informed consent rather than hide truth or cheat patients. The precondition of patients' satisfaction is based on mutual heartfelt trust between nurses and patients. Second, professional quality, which is always a golden promise to allow insurance of patients' safety, includes proficient using of new emerged medical devices, timely updating advanced knowledge, and capacity to resolve problematic issues etc $[3,4]$. By which nursing can easily explain the worrisome from patients, to correct physicians' medical errors, and also have better observation of patients' changes. Third, ward governance/ organizational performance, which is a soft power to produce or create comfortable environment, we all well know, clean, neat wards, always leave patients deep impressions as a symbol of positive outlook[5]. Notably, if the admitted patients beyond the accumulated peak or nursing service capacity, we should take steps to keep wards in good order. Otherwise, messy working flow program will pull patients on the edge of cliff.

In any way, nursing leadership is a leading power, learning more from practice, enriched in the practice, and strengthened for the practice [6]. 


\section{Declaration}

All authors declare that they have no conflict interests concerning on the manuscript.

\section{References}

1. Grohar-Murray M E, DiCroce H R, Langan J C. Leadership and management in nursing. Pearson. 2016;

2. Daly J, Speedy S, Jackson D. Leadership and nursing: contemporary perspectives. Elsevier Health Sciences. 2015;

3. Mette M J. Impetus to transform: essential nursing leadership development through simulation. 2015;
4. Wong C A, Cummings G G, Ducharme L. The relationship between nursing leadership and patient outcomes: a systematic review update. Journal of nursing management. 2013;21(5): 709-724. Doi:10.1111/ jonm.12116

5.Nezafati M. Component of transformational leadership and its relationship with organizational performance. International Journal of Humanities and Cultural Studies. 2016;1(1): 2001-2007.

6. Cutcliffe J and Cleary M. Nursing Leadership, Missing questions, and the elephant (s) in the room: problematizing the discourse on nursing leadership. Issues in Mental Health Nursing. 2015; 36(10): 817-825. Doi: 10.3109/01612840.2015.1042176 